\title{
In vitro evaluation of electroporated gold nanoparticles and extremely-low frequency electromagnetic field anticancer activity against Hep-2 laryngeal cancer cells
}

\author{
Mohammed A. Alshehri ${ }^{1}$, Piotr M. Wierzbicki ${ }^{2}$, Hassan F. Kaboo ${ }^{3}$, \\ Mohamed S.M. Nasr³, Mohamed E. Amer ${ }^{4}$, Tamer M.M. Abuamara3, \\ Doaa A. Badr5 ${ }^{5}$ Kamel A. Saleh ${ }^{1}$, Ahmed E. Fazary ${ }^{5 *}$, Aly F. Mohamed ${ }^{* * *}$ \\ ${ }^{1}$ Department of Biology, Science Collage, King Khalid University, Abha, Saudi Arabia \\ ${ }^{2}$ Department of Histology, Medical University of Gdansk, Gdansk, Poland \\ ${ }^{3}$ Histology Department, Faculty of Medicine, Al-Azhar University, Cairo, Egypt \\ ${ }^{4}$ Histology Department, Faculty of Medicine, Al-Azhar University, Damietta, Egypt \\ ${ }^{5}$ Applied Research Department, Research \& Development Sector, Egyptian Organization for \\ Biological Products and Vaccines (VACSERA Holding Company), Giza, Egypt \\ ${ }^{6}$ The International Center for Advanced Researches (ICTAR-Egypt), Cairo, Egypt
}

\begin{abstract}
Introduction. The extremely-low frequency electromagnetic field (ELFEMF) has been proposed for use in cancer therapy since it was found that magnetic waves interfere with many biological processes. Gold nanoparticles (Au-NPs) have been widely used for drug delivery during cancer in vitro studies due to their low cytotoxity and high biocompatibility. The electroporation of cancer cells in a presence of Au-NPs (EP Au-NPs) can induce cell apoptosis, alterations of cell cycle profile and morphological changes. The impact of ELFEMF and EP Au-NPs on morphology, cell cycle and activation of apoptosis-associated genes on Hep-2 laryngeal cancer cell line has not been studied yet.

Materials and methods. ELFEMF on Hep-2 cells were carried out using four different conditions: 25/50 mT at 15/30 min, while Au-NPs were used as direct contact (DC) or with electroporation (EP, 10 pulses at 200V, equal time intervals of $4 \mathrm{sec}$ ). MTT assay was used to check the toxicity of DC Au-NPs. Expression of CASP3, $P 53, B A X$ and $B C L 2$ genes was quantified using qPCR. Cell cycle was analyzed by flow cytometry. Hematoxylin and eosin (HE) staining was used to observe cell morphology.

Results. Calculated $\mathrm{IC}_{50}$ of DC Au-NPs $24.36 \mu \mathrm{M}(4.79 \mu \mathrm{g} / \mathrm{ml})$ and such concentration was used for further DC and EP AuNPs experiments. The up-regulation of pro-apoptotic genes $(C A S P 3, P 53, B A X)$ and decreased expression of $B C L 2$, respectively, was observed for all analyzed conditions with the highest differences for EP AuNPs and ELFEMF $50 \mathrm{mT} / 30 \mathrm{~min}$ in comparison to control cells. The highest content of cells arrested in G2/M phase was observed in ELFEMF-treated cells for $30 \mathrm{~min}$ both at 25 or $50 \mathrm{mT}$, while the cells treated with EP AuNPs or ELFEMF $50 \mathrm{mT} / 15 \mathrm{~min}$ showed highest ratios of apoptotic cells. HE staining of electroporated cells and cells exposed to ELFEMF's low and higher frequencies for different times showed nuclear pleomorphic
\end{abstract}

\footnotetext{
Correspondence address: *Professor Ahmed E, Fazary

Applied Research Department, Research \& Development

Sector, Egyptian Organization for Biological Products and

Vaccines (VACSERA Holding Company),

51 Wezaret El-Zeraa St., Agouza, Giza, Egypt

e-mail: aefazary@gmail.com

https://orcid.org/0000-0002-2614-4104

**Professor Aly Fahmy Mohamed

The International Center for Advanced Researches

(ICTAR-Egypt), Cairo, Egypt

e-mail: fahmy.aly@gmail.com
} 
cells. Numerous apoptotic bodies were observed in the irregular cell membrane of neoplastic and necrotic cells with mixed euchromatin and heterochromatin.

Conclusions. Our observations indicate that treatment of Hep-2 laryngeal cancer cells with ELFEMF for 30 min at 25-50 $\mathrm{mT}$ and EP Au-NPs can cause cell damage inducing apoptosis and cell cycle arrest. (Folia Histochemica et Cytobiologica 2019, Vol. 57, No. 4, 159-167)

Key words: gold nanoparticles; electroporation; extremely-low frequency electromagnetic field; Hep-2 cells; apoptosis; qPCR

\section{Introduction}

Laryngeal cancer most often refers to squamous cell carcinoma of the larynx. Other malignant tumors of the larynx (e.g., sarcoma, lymphoma, neuroendocrine tumors) are extremely rare in comparison. This disease consists of malignant tumors of mucosal origin that originate from the supra-glottis, glottis, and sub-glottis. Electromagnetic fields (EMFs) have been employed as useful tools in medical diagnosis. Recently, the use of EMFs has been expanded for therapeutic purposes because their interactions with living matter produce effects that initiate, accelerate or inhibit biological processes. Frequencies below $300 \mathrm{~Hz}$ are known as extremely low-frequency electromagnetic fields (ELFEMFs) which do not break molecular bonds due to low energy; therefore not causing direct DNA damage. Additionally, ELFEMFs are non-invasive and non-ionizing and even have non-thermal effects on cells and tissues. These properties have led to studies on the influence of ELFEMF on the development of various diseases, including cancer. While some researchers associate ELFEMF exposure with carcinogenesis $[1,2]$, other studies on experimental models and human cancers have shown that ELFEMF does not increase the risk of development of several tumor types, including liver cancer [3-5]. The ELFEMF treatment with tumor-specific frequencies is feasible and well-tolerated and may show positive biological efficacy in patients with advanced tumors [3-5]. Moreover, the exposure of female C3H/HeJ mice bearing human mammary adenocarcinoma to a frequency of $120 \mathrm{~Hz}$ at intensities of 4 and $5 \mathrm{mT}$ resulted in a significant reduction in the growth of the tumors, which is a phenomenon associated with inhibition of angiogenesis [6]. Also, the exposure of female athymic nude mice with human breast cancer xenografts to a frequency of $120 \mathrm{~Hz}$ with an intensity of $15 \mathrm{mT}$, either alone or in combination with gamma radiation, resulted in decreased growth or reduced vascularization of the tumors [7]. Similarly, the effect of $50 \mathrm{~Hz}$ at $0.5 \mu \mathrm{T}$ and $0.5 \mathrm{mT}$ on the development of chemically induced foci in rat livers showed a slight inhibition of foci formation [8]. Further studies on
ELFEMFs' impact on cancer cells are demanded since the current observations are insufficient as a proof of ELFEMF inhibition of carcinogenesis. The anticancer activity of gold nanoparticles (Au-NPs) has been studied against Dalton's lymphoma ascites (DLA) cell lines, human epithelial type 2 (Hep-2) cell lines and human leukemic monocyte lymphoma respectively $[9,10]$. The anticancer effect of silver and gold nanoparticles against HepG-2 and lung cancer (A549) cell lines was performed [11, 12]. The results showed a good cytotoxic activity against the tested cancer cell lines. The concentration of Au-NPs plays an important role in their anticancer activity. Au-NPs showed expected effects against A549 cells in wide spectrum of concentrations: $100,1 \mathrm{~g}$, by $50 \mu \mathrm{g}, 25 \mu \mathrm{g}$ and $1 \mu \mathrm{g}$. The lowest inhibitory effect on cells was observed for the concentration of $10 \mu \mathrm{g}$. The cytotoxic effect of Au-NPs is the result of active physicochemical interaction of gold atoms with the functional groups of intracellular proteins, as well as with the nitrogen bases and phosphate groups in DNA. So, the aim of this study was to use electroporation in a presence of Au-NPs and ELFEMF effect on laryngeal carcinoma cell line (Hep-2) to evaluate genetic alteration under the effect of both electroporated Au-NPs and ELFEMF at different time and frequencies and related pathological changes [7].

\section{Materials and methods}

Cell culture. Laryngeal adenocarcinoma cell line (Hep-2, ATCC: CCL-23) was kindly supplied from the Holding company, Tissue Culture Department, for production of vaccines, sera, and drugs (VACSERA, Giza, Egypt). Cells were maintained in MEM-E medium supplemented with $10 \%$ fetal bovine serum (GIBCO, Thermo Fisher Scientific, Waltham, MA, USA) in a humidified atmosphere of $5 \%$ $\mathrm{CO}_{2}$ at $37^{\circ} \mathrm{C}$ (Jouan SA, Saint-herblain, Pays de la Loire, France). Cells were maintained according to manufacturing protocol where the growth medium was decanted and cells were washed with phosphate buffer saline (Adwia Pharmaceuticals, El Sharkeya, Egypt). Cells were treated with $0.25 \%$ trypsin enzyme and $0.05 \%(\mathrm{v} / \mathrm{v})$ EDTA (GIBCO) for $5 \mathrm{~min}$ at $37^{\circ} \mathrm{C}$. Detached cells were splatted according to need. 
Cell Viability and Au-NPs $\mathrm{IC}_{50}$ evaluation (MTT Assay). Cytotoxicity was conducted according to the previous work [13] where human laryngeal cancer cells were propagated in $75 \mathrm{~cm}^{2}$ cell culture (TPP-Swiss) as previously mentioned according to the previously reported work [13]. Cells were plated at a concentration of $2 \times 10^{5} \mathrm{cell} / \mathrm{ml}$ in $96-w e l l$ cell culture plates and incubated at $37^{\circ} \mathrm{C}$ for $24 \mathrm{~h}$ to achieve confluence. The growth medium was decanted and fresh medium containing 2 fold serially diluted Au-NPs dispensed to pre-cultured plate. $24 \mathrm{hrs}$ later, dead cells were washed out using phosphate buffer saline ( $\mathrm{PBS}, \mathrm{pH}=7.2 \pm 0.2$ (Adwia) and $50 \mu$ l of MTT (3-(4,5-dimethylthiazol-2-yl)-2,5-diphenyltetrazolium bromide) stock solution $(0.5 \mathrm{mg} / \mathrm{ml})$ were added per well. After $4 \mathrm{~h}$ incubation period at $37^{\circ} \mathrm{C}$, the supernatant was discarded and the formazan precipitate was solubilized by addition of $50 \mu \mathrm{l} /$ well of dimethyl sulfoxide (DMSO). Plates were incubated in the dark for $30 \mathrm{~min}$ at $37^{\circ} \mathrm{C}$ and absorbance was determined at a wavelength of $570 \mathrm{~nm}$ using microplate reader (ELx-800, Bio-Tek Instruments, Inc, Winooski, VT, USA). The cell viability percentage was calculated using the following formula: Viability percentage $(\%)=$ Mean OD of test dilution $\times 100 /$ Mean OD of control wells. The $\mathrm{IC}_{50}$ value was determined using GraphPad Prism software (v.6, GraphPad Software, La Jolla, CA, USA). For cell cycle and apoptotic profile, Hep-2 cells were pre-cultured in $25 \mathrm{~cm}^{2}$ surface area (SA) cell culture flasks, treated with the $\mathrm{IC}_{\mathbf{5 0}}$ of Au-NPs in MEM-E medium post decanting the growth medium. $24 \mathrm{~h}$ later the affected cells were collected and divided for cell cycle and genetic analysis, the cells were harvested and fixed gently with $70 \%$ (v/v) ethanol in PBS, maintained at a temperature of $4^{\circ} \mathrm{C}$ overnight, and re-suspended in PBS containing $40 \mu \mathrm{g} / \mathrm{ml}$ PI (propidium iodide), $0.1 \mathrm{mg} / \mathrm{ml} \mathrm{RNase}$ and $0.1 \%(\mathrm{v} / \mathrm{v})$ Triton X-100 in a dark room. After $30 \mathrm{~min}$ at $37^{\circ} \mathrm{C}$, the cells were analyzed using a flow cytometer (Becton-Dickinson, San Jose, CA, USA) equipped with an argon ion laser at a wavelength of $488 \mathrm{~nm}$. The cell cycle and sub-G1 group were determined and analyzed, as described previously.

Electroporation of laryngeal cancer cells. Hep-2 cells were seeded in $75 \mathrm{~cm}^{2}$ cell culture flasks and incubated at $37^{\circ} \mathrm{C}$ $\left(5 \% \mathrm{CO}_{2}\right)$ until attachment. Cells were trypsinized and pelleted using cold centrifugation (Jouan-Ki21, ParisTech, France $)$, the supernatant was decanted and Au-NPs $(0.5 \mu \mathrm{M} /$ $/ \mathrm{mL}$ ) were added to $0.5 \mathrm{~mL}$ of Hep- 2 cells and mixed well. Cells - Au-NPs (at the final concentration calculated as IC50 for DC AuNPs) mix was placed in the sterile MicroPulser electroporation cuvette (Biorad, Hercules, CA, USA). Ten pulses were made at $200 \mathrm{~V}$ and applied to the cells at equal time intervals of $4 \mathrm{~s}$. Negative control was considered.

Extremely-low frequency electromagnetic field treatment (ELFEMF). Four sterile test tubes of detached Hep-2 cancer cell line $\left(2 \times 10^{6} \mathrm{cell} / \mathrm{ml} /\right.$ tube $)$ were categorized, where two of the tubes were subjected to the electromagnetic field as $25 \mathrm{mT}$ for 15 and $30 \mathrm{mins}$ in a cooling atmosphere. The other two tubes were exposed to the electromagnetic field at $50 \mathrm{mT}$ for the same time intervals. The apparatus (Medical Physics, Swiss Tropical and Public Health Institute, Basel, Switzerland) was adjusted for each magnetic field frequency using a teslameter set for justification of a magnetic field. The test tubes were kept inside the center of the coil producing EMF. The test tubes were tested for apoptotic profile regarding the pro-and anti-apoptotic genes (P53, Bd-2, Bax, caspase-3), cell cycle and histological profile were considered.

Hematoxylin and eosin staining of Hep-2 cells. Fifty microliters of Au-NPs electroporated and ELFEMF exposed cells were dispensed on clean slides ( 3 for each treatment). Slides were air-dried, methanol fixed and rehydrated in descending concentrations of alcohol $(100 \%, 90 \%, 75 \%$ and $50 \%$ ). Slides were washed in distilled water for $5 \mathrm{~min}$. The slides were immersed in filtered hematoxylin (HE) stain for $3 \mathrm{~min}$ and washed with distilled water twice. Slides were immersed in filtered eosin stain for 5 seconds and washed with distilled water. Dried slides were immersed in xylene, mounted with Canada balsam then coverslips were placed and left to dry. Ten microscopic fields of each slide were photomicrographed using the power of $400 \times$. This was done using a digital camera (Canon, Tokyo, Japan), which was mounted on a light microscope. Images were transferred to the computer system for analysis. Field selection was based on the presence of the highest number of apoptotic cells. The photomicrographs were qualitatively evaluated for the presence of morphological criteria of apoptosis.

Expression of apoptosis-related genes. Total RNA was extracted from control, ELFEMF (25/50 mT for 15 and $30 \mathrm{~min}), 1 \mathrm{mM}$ Au-NPs direct contact and electroporated exposed cells, respectively using RNeasy Mini Kit (Qiagen, Germantown, MD, USA) according to manufacturer's instructions. The concentration of extracted RNA was evaluated using a Beckman dual spectrophotometer (Beckman Instruments, Ramsey, MN, USA). The expression level of apoptosis-related genes; P53 (F: 5'-TCAGATCCTAGC GTCGAGCCC-3' \& R: 5'-GGGTGTGGAATCAACCCACAG-3'), $B A X$ (F: 5'-ATGGACGGGTCCGGGGAGCA-3' \& R: 5'-CCCAGTTGAAGTTGCCGTCA-3') and BCL2 (F: 5'-GTGAACTGGGGGAGGATTGT-3'\& R: 5'-GGAGAAATCAAACAGAGGCC-3') CASP3 (F 5CTCGGTCTGGTACAGATGTCGA-3' \& R: (5- CATGGCTCAGAAGCACACAAAC-3) and housekeeping gene; $A C T B$ (F 5'- AGCGAGCATCCCCCAAAGTT-3'\& R: 5'-GGGCACGAAGGCTCATCATT-3) were determined using real-time PCR. $10 \mathrm{ng}$ of the extracted total RNA from each sample was used for cDNA synthesis using high capacity cDNA reverse transcriptase kit (Applied 
Biosystems-Thermo Fischer Scientific, USA). The obtained cDNA was subsequently amplified using Sybr Green I PCR master kit (Thermo Fisher Scientific Inc., Lithuania) using Step One apparatus (Applied Biosystems), as follows: $10 \mathrm{~min}$ at $95^{\circ} \mathrm{C}$ for enzyme activation followed by 40 cycles of $15 \mathrm{~s}$ at $95^{\circ} \mathrm{C}, 20 \mathrm{~s}$ at $55^{\circ} \mathrm{C}$ and $30 \mathrm{~s}$ at $72^{\circ} \mathrm{C}$ for the amplification step. Changes in the expression of each target gene were normalized relative to the mean critical threshold (CT) values of $\beta$-actin as housekeeping gene by the $\Delta \mathrm{CT}$ method.

Cell cycle analysis. Cell cycle distribution was examined by measuring the DNA content of nuclei labeled with propidium iodide (PI). Au-NPs electroporated and ELFEMF treated Hep-2 cells were pelleted by cold centrifugation (Jouan Ki-21-France), washed with $1 \mathrm{ml}$ of cold PBS, centrifuged, and fixed in $70 \%$ cold ethanol at $+4^{\circ} \mathrm{C}$ for 24 hrs. Subsequently, cells were washed twice and treated with RNase A (20 mg/ml) and PI (20 mg/ml), FITC conjugated Annexin-V according to the protocol described by the manufacturer for $30 \mathrm{~min}$ at $37^{\circ} \mathrm{C}$ in the dark. Finally, cell cycle distribution analysis was performed using flow cytometry and the percentages of cells at G1, S and G2/M phases were calculated by flow cytometry (Becton-Dickinson).

Statistical analysis. All experiments were carried out three independent times. Results were statistically analyzed using GraphPad Prism v. 6.07 (GraphPad Software, San Diego, CA, USA) with the following tests: t-test between 2 subgroups, one-way analysis of variance (ANOVA) between more than two subgroups, regression analysis and Spearman's correlation test. All results were presented as mean \pm SD. The difference was considered statistically significant at $\mathrm{P}<0.05$.

\section{Results}

The toxicity test of Au-NPs was performed on Hep-2 cells and the results were shown in Figure 1. Based on that, the calculated $\mathrm{IC}_{50}$ concentration was $24.36 \mu \mathrm{M} /$ $\mathrm{ml}(4.79 \mu \mathrm{g} / \mathrm{ml})$. Such concentration of Au-NPs was used in further experiments with electroporation (EP Au-NPs) or by direct contact between Au-NPs and Hep- 2 cells (DC Au-NPs). The influence of ELFEMF on Hep-2 cells was carried out using four different magnetic induction/time values: $25 \mathrm{mT} / 15 \mathrm{~min}$, $25 \mathrm{mT} / 30 \mathrm{~min}, 50 \mathrm{mT} / 15 \mathrm{~min}$ and $50 \mathrm{mT} / 30 \mathrm{~min}$. The expression profile of three pro-apoptotic genes $(C A S P 3, P 53, B A X)$ and one anti-apoptotic gene (BCL2) of Au-NPs and ELFEMF treated cells showed statistically different ratios (Fig. 2). We found the highest expression of $C A S P 3, P 53$ and $B A X$ genes in EP Au-NPs and ELFEMFs cells at $50 \mathrm{mT} / 30 \mathrm{~min}$ (Fig. 2 A, B, C). Moreover, the tendency of increas-

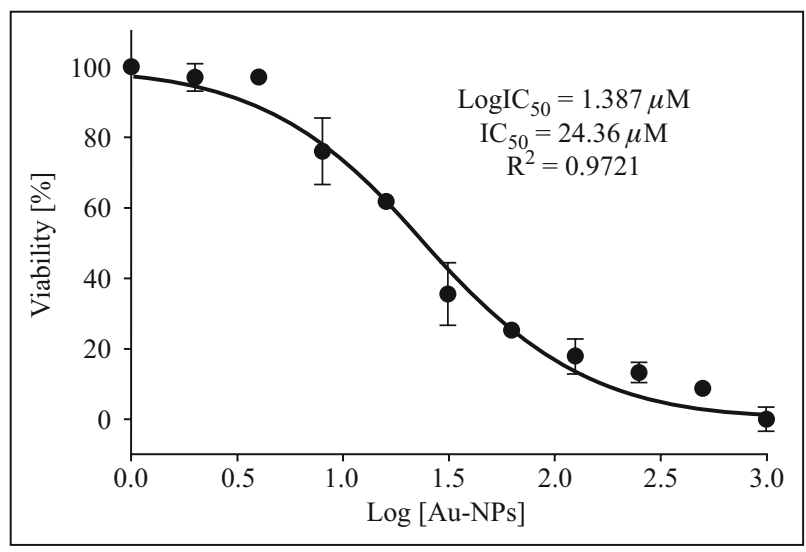

Figure 1. Evaluation of cytotoxicity of gold nanoparticles on Hep-2 cells using MTT assay. The calculated $\mathrm{IC}_{50}$ was 24.26 $\mu \mathrm{M}$ using Graphpad Prism software. The values obtained from three separate experiments are shown (mean \pm SD) and the nonlinear regression curve was added to plot, $\mathrm{R}^{2}=0.972$.

ing expression of pro-apoptotic genes was observed in higher magnetic field/time values $(\mathrm{P}>0.05$, data not shown). We found that the electroporation with Au-NPs influenced the expression of $C A S P 3, P 53$ and $B A X$ the similar way vs. direct contact with Au-NPs as increasing ELFEMF values. Regarding the BCL2 gene, we did not observe the association between ELFEMF values and BCL2 expression rate (except for the $25 / 15$ vs. $50 / 30 \mathrm{mT} / \mathrm{min}$ values). Again, we found that EP Au-NPs-treated Hep-2 cells presented the lowest ratio of BCL2 expression. The presented results showed that the electroporation with Au-NPs (at the concentration of $24.36 \mu \mathrm{M}$ ) as well as the usage of ELFEMF at $50 \mathrm{mT} / 30 \mathrm{~min}$ values activated the expression of analyzed pro-apoptotic genes and deactivated the expression of anti-apoptotic BCL2 gene at the highest values of tested conditions.

Next, we checked the influence of Au-NPs and ELFEMF on the cell cycle of Hep-2 cells (Fig. 3). The significant $\mathrm{G} 2 / \mathrm{M}$ phase arrest was observed for cells treated with all ELFEMFs (except for $50 \mathrm{mT} / 15 \mathrm{~min}$ ) values (Fig. 3C). It seems that the G2/M arrest was associated with prolonged time of exposure rather than higher dose of electromagnetic field. The similar pattern of ELFEMF impact was found in apoptotic cell distribution (Fig. 3D). Although the distribution of apoptotic cells in EP Au-NPs treated cells was higher than in control cells (Fig. 3D), we did not observed cellular arrest in any of analyzed cell cycle phases when cells were treated with gold nanoparticles.

The microscopic observation of ELFEMF exposed and Au-NPs electroporated cells showed morphologi- 

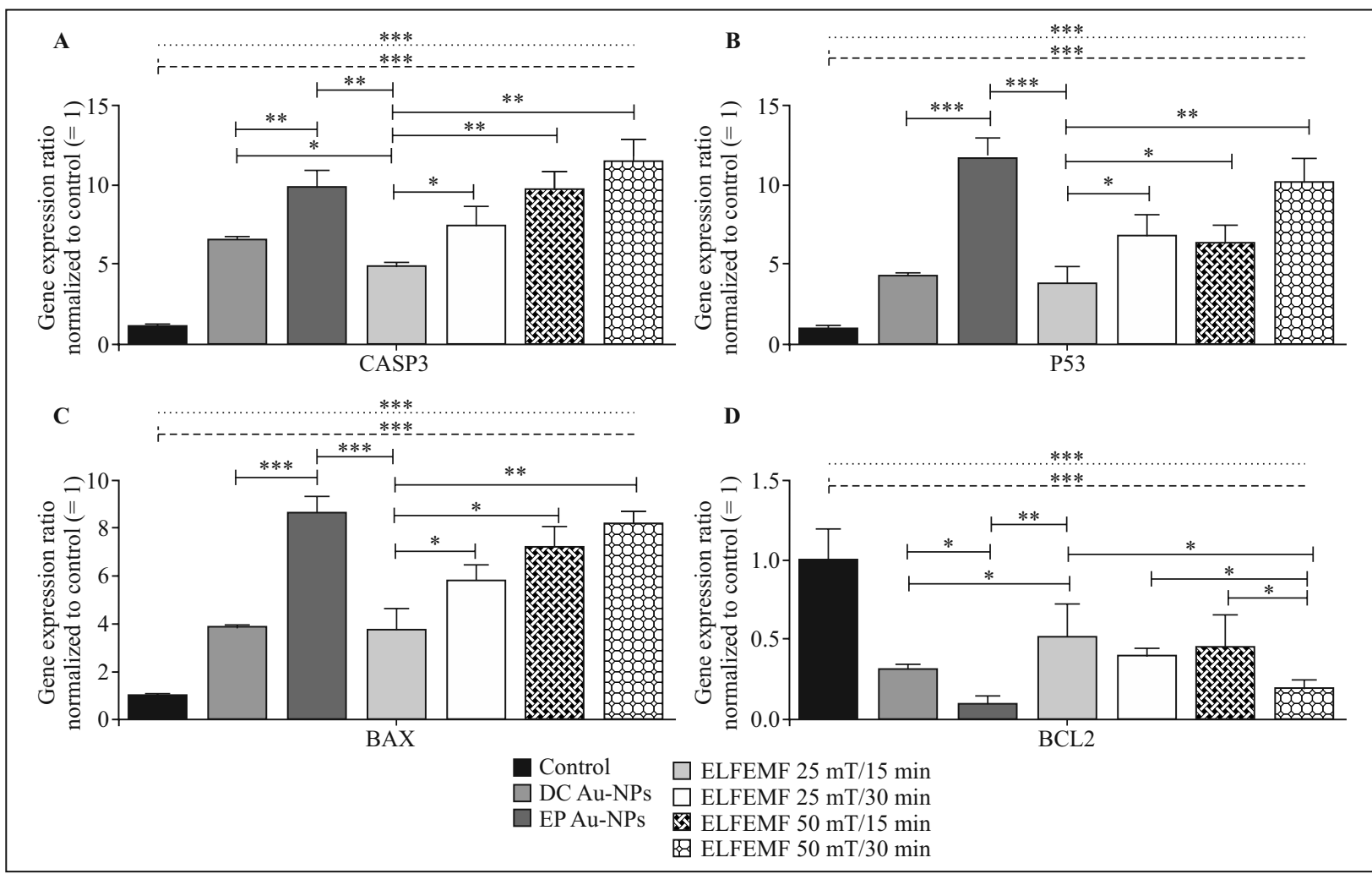

Figure 2. Expression analysis of the $C A S P 3, P 53, B A X$ and $B C L 2$ genes in Hep-2 cells at the mRNA level. Gene expression was assessed as described in the Materials and methods. (A-D) plots for CASP3, P53, BAX and BCL2 genes' expression ratios in cells after treatment with different conditions, respectively. Bars and whiskers represent mean \pm standard deviation normalized to control samples. ${ }^{*} \mathrm{P}<0.05,{ }^{* *} \mathrm{P}<0.01$, ${ }^{* * *} \mathrm{P}<0.001$; capped lines: t-test between subgroups; dotted line: one-way ANOVA between all subgroups; dashed line: t-test between control and tested cells, respectively. $C A S P 3$, caspase 3 gene; $P 53$, tumor protein 53 gene; $B A X$, BCL2 associated X; BCL2, B-cell lymphoma 2 gene; DC Au-NPs, direct contact gold nanoparticles; EP Au-NPs, electroporation with gold nanoparticles; ELFEMF, extremely-low frequency electromagnetic field.

cal differences in comparison to control cells (Fig. 4). Hematoxylin and eosin staining of control, Hep-2 cells, showed regular cellular pleomorphic and nuclear pleomorphic cells (Fig. 4A), Au-NPs electroporated Hep- 2 cells showed numerous apoptotic bodies, irregular cell membrane of neoplastic and necrotic cells with mixed euchromatin and heterochromatin (Fig. 4B). Also, Hep-2 cells showed numerous apoptotic bodies on post short term exposure to ELFEMF for $15 \mathrm{~min}$ at $25 \mathrm{mT}$ and neoplastic cells with nuclear fragmentation and apoptotic body on post longerterm cell exposure (Fig. 4C); 30 min at $25 \mathrm{mT}$ (Fig. 4D). Moreover, higher frequency at $50 \mathrm{mT}$ for $15 \mathrm{~min}$ (Fig. 4E), exposed cells showed numerous apoptotic bodies and irregular neoplastic cell membrane and clear necrosis with mixed euchromatin and heterochromatin ruptured cell membrane of necrotic cells on post cell exposure to $50 \mathrm{mT}$ for $30 \mathrm{~min}$ (Fig. 4F).

\section{Discussion}

The present work aimed to use ELFEMF and electroporation with Au-NPs as alternative ways of promotion apoptosis of human laryngeal cancer cells. Also, we aimed to preview the genetic and cell cycle alterations in Hep- 2 cells. The obtained data revealed that both electroporation in a presence of Au-NPs and cell exposure to ELFEMF could manage the death of cancer cells via apoptosis induction.

The present study indicated that intermittent exposure of laryngeal carcinoma cells (Hep-2) to a 25 and $50 \mathrm{mT}$ of ELFEMF affected cell cycle profile and proved these via noticed elevated up and down-regulation of apoptosis-related genes. Thus, we showed that apoptotic profile and $\mathrm{G} 2 / \mathrm{M}$ cellular arrest may play the crucial role in the biological effects of 25 and $50 \mathrm{mT}$ ELFEMF and related induction of DNA 


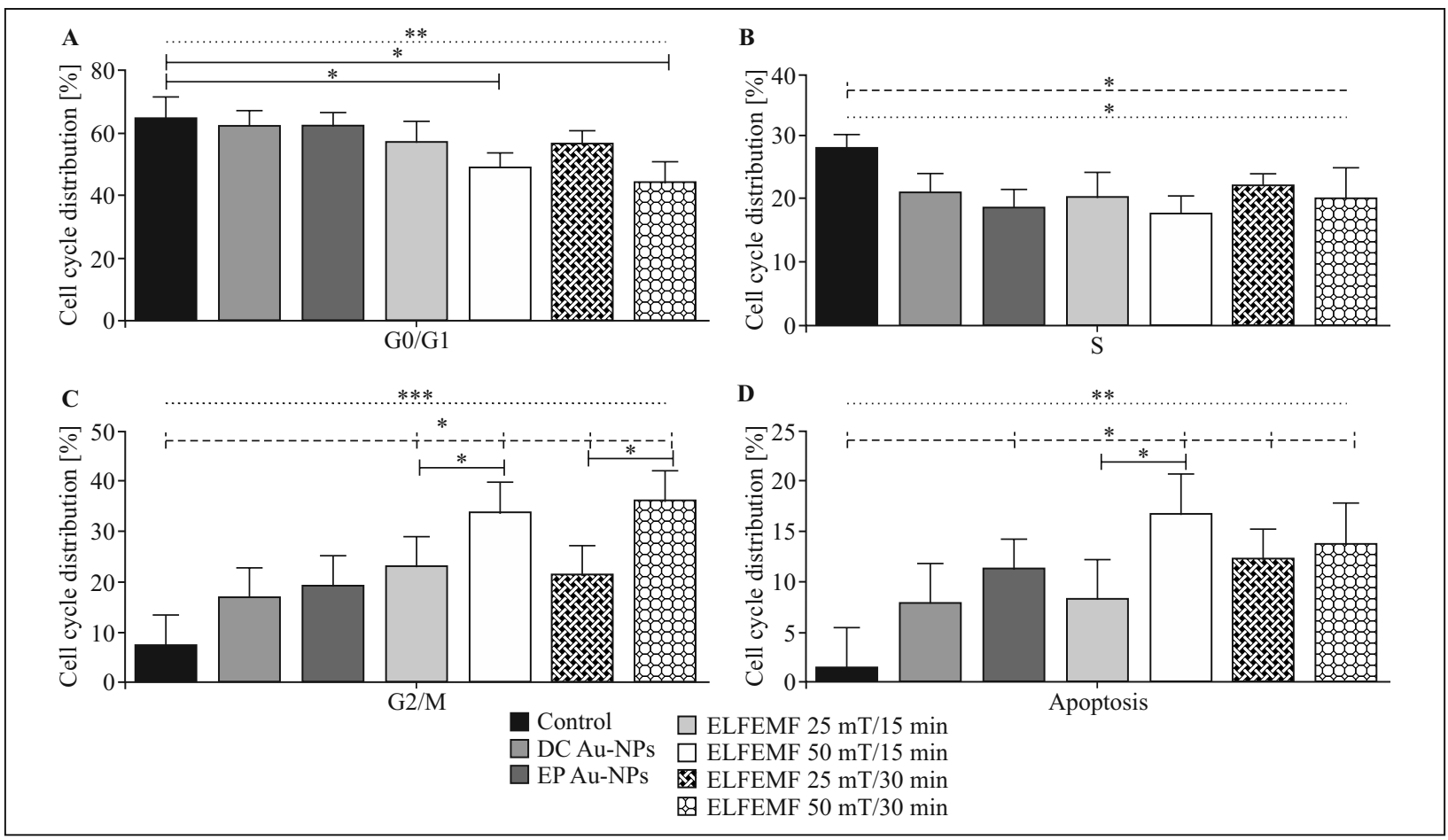

Figure 3. Evaluation of cell cycle of Hep-2 cells using flow cytometry. (A-D) G0/G1, S, G2/M phases and apoptotic cells' proportions of Hep- 2 cells. ${ }^{*} \mathrm{P}<0.05,{ }^{*} \mathrm{P}<0.01,{ }^{* * *} \mathrm{P}<0.001$; capped lines: t-test between subgroups; dotted line: oneway ANOVA between all subgroups; dashed line: t-test between control and tested cells, respectively. DC Au-NPs, direct contact gold nanoparticles; EP Au-NPs, electroporation with gold nanoparticles; ELFEMF, extremely-low frequency electromagnetic field.

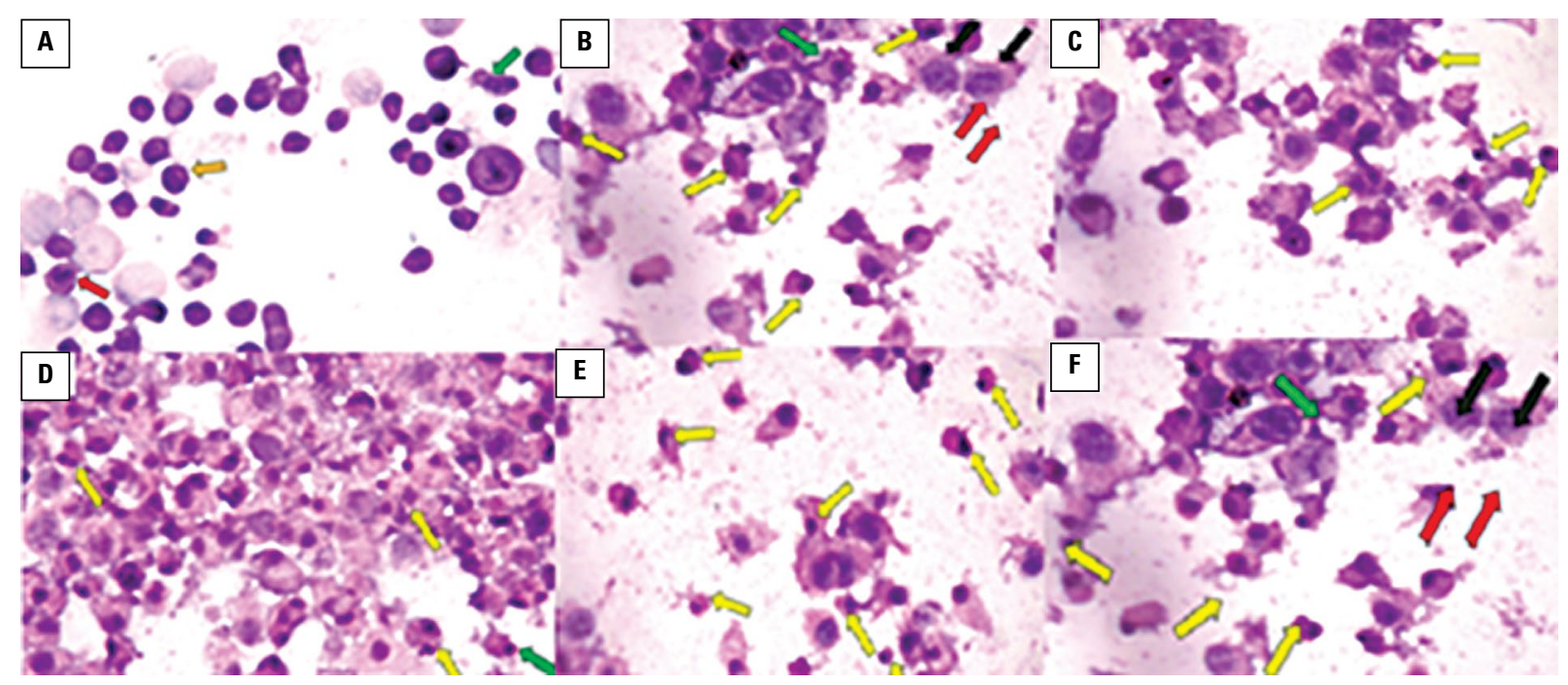

Figure 4. Microphotographs of Hep-2 cells after Au-NPs or ELFEMF treatment. A. Control, untreated Hep-2 cells present regular tumor cells (yellow arrow), cellular pleomorphism (green arrow) and nuclear pleomorphism (red arrow). B. Hep-2 Au-NPs electroporated cells show numerous apoptotic bodies (yellow arrows), irregular cell membrane of neoplastic cell (green arrow), necrotic cells with euchromatin and heterochromatin (red arrows) and ruptured cell membrane of necrotic cells (black arrows). C. Hep-2 cells showing numerous apoptotic bodies post short term exposure to ELFEMF for 15 min at $25 \mathrm{mT}$ (yellow arrows). D. Hep-2 cells showing neoplastic cells with nuclear fragmentation (yellow arrows) and apoptotic bodies (green arrow) post cell exposure for $30 \mathrm{~min}$ at $25 \mathrm{mT}$. E. Hep-2 cells showing numerous apoptotic bodies (yellow arrows) after cell exposure to $50 \mathrm{mT}$ for $15 \mathrm{~min}$. F. Hep- 2 cells showing numerous apoptotic bodies and irregular cell membrane of neoplastic cells (green arrow), necrotic cells (red arrows) and ruptured cell membrane of necrotic cells (black arrows) after cell exposure to $50 \mathrm{mT}$ for $30 \mathrm{~min}$. H\&E staining, magnification $\times 40$. 
strand breaks. On the other hand, it was observed that subjecting cells continuously to a constant electromagnetic field may induce adaptive mechanisms, protecting the genome from harmful influences [14]. The point of view concerning this way and effect was based on the continuous exposure of people to such frequencies via different magnetic field sources such as radio and microwave in their homes. The potential of ELFEMF to exert harmful biological effects on human health is of increasing concern. It has been reported that DNA damage may be involved in cell proliferation, apoptosis as well as cell cycle $[15,16]$.

The presence of Au-NPs inside the cells allowed the introduction and progress of cell damage, especially cancerous cells. On the other hand, it has been noticed that the cells that were exposed to the ELFEMF have developed a high rate of cellular damage. This cellular damage was developed by the irreversible induction of pores in the cell membrane due to the overlapping between the externally applied ELFEMF and the magnetic properties of the cell membranes. In addition to the effectiveness of the magnetic field on the cancerous cells, Au-NPs activate the signaling pathways through acting on the membrane proteins that leads to the inhibition of the cancer cells proliferation. It was previously observed that the gold nanoparticles have the ability to enter the cells through the endocytosis, which produces mitochondrial dysfunction, formation of reactive free radicals and the destruction of nucleic acid and cellular proteins [17]. Hence, all the used effects allow the inhibition of cellular proliferation. Therefore, the utilizing of gold nanoparticles in the presence of electroporation and the effect of extremely-low electromagnetic field has shown remarkable effects. This was done by the activation of Au-NPs to start entering the tumor cells, especially through electroporation physics enhancers accordingly displaying a remarkable ability to treat the tumor cells. It was observed that the use of electroporation in the presence of gold nanoparticles can be effective to induce apoptosis in the Hep-2 cells. Moreover, the combination of electroporation and Au-NPs had moderate effect on the studied neoplastic cells. Hence, the effect on pro-apoptotic genes (P53 and $B A X)$ and anti-apoptotic genes (BCL2) was viewed to be significant in the presence of combined action of gold nanoparticles and electroporation and the ELFEMF treatment with $50 \mathrm{mT}$ and $100 \mathrm{mT}$.

The influence of size, shape, and surface modification on cytotoxicity of gold nanoparticles to human Hep-2 and canine MDCK cells was investigated by Zhang et al. [11]. Au-NPs cell treatment revealed that cell death induced predominately within one hour through apoptosis induced gene expression, whereas cell death by free cetyltrimethylammonium-bromide (CTAB) was a time- and dose-dependent. Both positively and negatively surface-charged polymer-coated gold nanorods GNRs showed similar levels of cytotoxicity, suggesting the significance of surface functionality rather than surface charge in this case [11].

As the interaction of gold nanoparticles with cells relies on properties of nanoparticles, the cytotoxicity is complex and still under debate. In a previously published work, they found that cetyltrimethylammonium-bromide (CTAB) encapsulated gold nanorods (GNRs) were relatively higher cytotoxic than gold nanorods (GNRs) undergone further polymer coating and citrate stabilized gold nanospheres (GNSs) [11].

The toxicity of CTAB-encapsulated GNRs was mainly caused by CTAB on GNRs' surface but not free CTAB in the solution. On the contrary to our data, Brisdelli and coworkers recorded that lower frequency ELF-MF $(1 \mathrm{mT} ; 50 \mathrm{~Hz})$ enhanced the apoptosis and that ULEMF $(25 / 50 \mathrm{mT} ; 50 \mathrm{~Hz})$ enhanced the apoptosis and cell arrest in human laryngeal carcinoma Hep-2 cells [18]. Four different compounds, namely vinblastine, etoposide, quercetin, and resveratrol, enhanced apoptosis in human K562 chronic myeloid leukemia cells. The exposure to ELFEMF did not affect growth and viability of untreated K562 cells and did not influence the anti-proliferative effects of resveratrol, vinblastine, and etoposide [18]. On the contrary, in quercetin treated cells, exposure to ELFEMF significantly reduced the percentage of apoptotic cells and the caspase- 3 activity and modified the cell cycle profile especially after 48 hours of exposure. In addition, the simultaneous treatments for 24 hours with quercetin plus ELFEMF increased Bcl-2 protein expression and prevented quercetin-induced downregulation of Mcl-1 and Bcl-xL [18].

The ELFMF-dependent modulation of the expression of anti-apoptotic Bcl-2 family and $\mathrm{Hsp} 70$ proteins could act as a pro-survival mechanism in K562 cells [18]. ELFEMF seems to produce several biological effects such as changes in cell proliferation, cell differentiation, cell cycle and enzyme activity [19-22]. Moreover, ELFEMF was found to affect cellular redox homeostasis, modulation of physiological functions such as mitochondrial membrane potential, $\mathrm{Ca}^{+2}$ signaling and homeostasis, and ATP synthesis [23-25]. Alterations in the apoptosis process are involved in the pathogenesis of many types of cancer [26]. There is evidence implicating ELFEMF in the development of this disease in humans [27], and many in vitro studies have also reported correlation between apoptotic process and ELFEMF. The latter has been involved in the reduction or delay of cell apoptosis process, as well as in its stimulation [28, 29]. 
Additionally, some studies reported evidence suggesting the combined effects of ELFEMF and various chemicals and physical agents in modulating the apoptotic cascade [30,31]. However, current research is characterized by conflicting data, and synergistic and/ /or antagonistic effect induced by ELFEMF has been described in $\mathrm{H}_{2} \mathrm{O}_{2}$-treated erythroleukemia cell line [32]. Also, our data was on the contrary of the previous work recording that the effects of $50 \mathrm{~Hz}$ ELFEMF exposure on the growth of GC-2 and cell viability was detected with the CCK-8 kit following $50 \mathrm{~Hz}$ ELFEMF exposure at different magnetic intensities for 72 hours to explore the effects of the ELFEMF on the growth of GC-2 cells [33]. Data showed that the $50 \mathrm{~Hz}$ ELFEMF did not markedly affect the morphology or viability (CCK-8) of GC-2 cells. Also, the effect of $50 \mathrm{~Hz}$ ELFEMF exposure on the apoptosis and cell cycle of GC-2 cells result showed that $50 \mathrm{~Hz}$ (ELFEMF) did not induce apoptosis in GC-2 cells compared with the same group [33]. Additionally, the percentages of G1-, S-, and G2-M phase cells did not significantly differ between the exposed groups post-treatment with $50 \mathrm{~Hz}$ ELFEMF for 72 hours. These findings confirmed that $50 \mathrm{~Hz}$ ELFEMF did not induce apoptosis or cell cycle arrest in GC-2 cell [34-36].

Based on the presented data, it could be concluded that the treatment of Hep-2 cancer cell with ELFEMF and electroporation with Au-NPs can cause cell damage inducing cell cycle arrest and apoptosis. Apoptotic and cell cycle profiles were cell type, time and ELFEMF frequency dependent. Usage of either Au-NPs-electroporation or ELFEMF in anti-cancer therapy may be a promising cancer therapy tool, may substitute or enhance the radio-, chemotherapy and surgical therapy approaches with least adverse effects. More intensified trials are recommended on different cancer cell lines as well as in vivo studies and different formulation of different nanoparticles shapes and concentrations must be validated.

\section{Acknowledgement}

The authors extend their appreciation to the Deanship of Scientific Research at King Khalid University, Abha, Saudi Arabia for funding this work through General Research Project under grant number G.R.P. 1/9/38-38

\section{References}

1. Girgert R, Schimming H, Körner W, et al. Induction of tamoxifen resistance in breast cancer cells by ELF electromagnetic fields. Biochem Biophys Res Commun. 2005; 336(4): 1144-1149, doi: 10.1016/j.bbrc.2005.08.243, indexed in Pubmed: 16168388 .

2. Chen G, Upham BL, Sun W, et al. Effect of electromagnetic field exposure on chemically induced differentiation of friend erythroleukemia cells. Environ Health Perspect.
2000; 108(10): 967-972, doi: 10.1289/ehp.00108967, indexed in Pubmed: 11049817.

3. Barbault A, Costa FP, Bottger B, et al. Amplitude-modulated electromagnetic fields for the treatment of cancer: discovery of tumor-specific frequencies and assessment of a novel therapeutic approach. J Exp Clin Cancer Res. 2009; 28: 51, doi: 10.1186/1756-9966-28-51, indexed in Pubmed: 19366446.

4. Galloni P, Marino C. Effects of $50 \mathrm{~Hz}$ magnetic field exposure on tumor experimental models. Bioelectromagnetics. 2000; 21(8): 608-614, doi: 10.1002/1521-186x(200012)21:8<608::aid-bem7>3.0.co;2-z, indexed in Pubmed: 11102951.

5. Yasui M, Kikuchi T, Ogawa M, et al. Carcinogenicity test of $50 \mathrm{~Hz}$ sinusoidal magnetic fields in rats. Bioelectromagnetics. 1997; 18(8): 531-540, doi: 10.1002/(sici)1521-186x(1997)18: 8<531::aid-bem1>3.0.co;2-3, indexed in Pubmed: 9383241.

6. Williams CD, Markov MS, Hardman WE, et al. Therapeutic electromagnetic field effects on angiogenesis and tumor growth. Anticancer Res. 2001; 21(6A): 3887-3891, indexed in Pubmed: 11911264.

7. Cameron IL, Sun LZ, Short N, et al. Therapeutic Electromagnetic Field (TEMF) and gamma irradiation on human breast cancer xenograft growth, angiogenesis and metastasis. Cancer Cell Int. 2005; 5: 23, doi: 10.1186/1475-2867-5-23, indexed in Pubmed: 16045802.

8. Rannug A, Holmberg B, Ekström T, et al. Rat liver foci study on coexposure with $50 \mathrm{~Hz}$ magnetic fields and known carcinogens. Bioelectromagnetics. 1993; 14(1): 17-27, doi: 10.1002/ bem.2250140105, indexed in Pubmed: 8442779.

9. Sriram MI, Kanth SB, Kalishwaralal K, et al. Antitumor activity of silver nanoparticles in Dalton's lymphoma ascites tumor model. Int J Nanomedicine. 2010; 5: 753-762, doi: 10.2147/ /IJN.S11727, indexed in Pubmed: 21042421.

10. Repacholi MH, Greenebaum B. Interaction of static and extremely low frequency electric and magnetic fields with living systems: health effects and research needs. Bioelectromagnetics. 1999; 20(3): 133-160, doi: 10.1002/(sici)1521-186x(1999)20:3<133::aidbem1>3.0.co;2-o, indexed in Pubmed: 10194557.

11. Zhang Y, Xu D, Li W, et al. Effect of size, shape, and surface modification on cytotoxicity of gold nanoparticles to human Hep-2 and canine MDCK cells. J Nanomaterials. 2012; 2012: 1-7, doi: 10.1155/2012/375496.

12. Rajeshkumar S. Anticancer activity of eco-friendly gold nanoparticles against lung and liver cancer cells. J Genet Eng Biotechnol. 2016; 14(1): 195-202, doi: 10.1016/j.jgeb.2016.05.007, indexed in Pubmed: 30647615.

13. Lim HK, Asharani PV, Hande MP, et al. Cytotoxicity and genotoxicity of silver nanoparticles in human cells. ACS Nano. 2009; 3(2): 279-290, doi: 10.1021/nn800596w, indexed in Pubmed: 19236062.

14. Artacho-Cordón F, Salinas-Asensio Md, Calvente I, et al. Could radiotherapy effectiveness be enhanced by electromagnetic field treatment? Int J Mol Sci. 2013; 14(7): 14974-14995, doi: 10.3390/ijms140714974, indexed in Pubmed: 23867611.

15. Kah JC, Wong KYi, Neoh KG, et al. Critical parameters in the pegylation of gold nanoshells for biomedical applications: an in vitro macrophage study. J Drug Target. 2009; 17(3): 181-193, doi: 10.1080/10611860802582442, indexed in Pubmed: 19016072.

16. Bailon P, Won CY. PEG-modified biopharmaceuticals. Expert Opin Drug Deliv. 2009; 6(1): 1-16, doi: 10.1517/17425240802650568, indexed in Pubmed: 19236204.

17. Behzadi S, Serpooshan V, Tao W, et al. Cellular uptake of nanoparticles: journey inside the cell. Chem Soc Rev. 2017; 46(14): 4218-4244, doi: 10.1039/c6cs00636a, indexed in Pubmed: 28585944 . 
18. Brisdelli F, Bennato F, Bozzi A, et al. ELF-MF attenuates quercetin-induced apoptosis in K562 cells through modulating the expression of Bcl-2 family proteins. Mol Cell Biochem. 2014; 397(1-2): 33-43, doi: 10.1007/s11010-014-2169-1, indexed in Pubmed: 25084985.

19. Frederix F, Friedt JM, Choi KH, et al. Biosensing based on light absorption of nanoscaled gold and silver particles. Anal Chem. 2003; 75(24): 6894-6900, doi: 10.1021/ac0346609, indexed in Pubmed: 14670050.

20. Hainfeld JF, Slatkin DN, Smilowitz HM. The use of gold nanoparticles to enhance radiotherapy in mice. Phys Med Biol. 2004; 49(18): N309-N315, doi: 10.1088/0031-9155/49/18/n03, indexed in Pubmed: 15509078.

21. Paciotti GF, Myer L, Weinreich D, et al. Colloidal gold: a novel nanoparticle vector for tumor directed drug delivery. Drug Deliv. 2004; 11(3): 169-183, doi: 10.1080/10717540490433895, indexed in Pubmed: 15204636.

22. Podsiadlo P, Sinani VA, Bahng JH, et al. Gold nanoparticles enhance the anti-leukemia action of a 6-mercaptopurine chemotherapeutic agent. Langmuir. 2008; 24(2): 568-574, doi: 10.1021/la702782k, indexed in Pubmed: 18052300.

23. Niidome T, Yamagata M, Okamoto Y, et al. PEG-modified gold nanorods with a stealth character for in vivo applications. J Control Release. 2006; 114(3): 343-347, doi: 10.1016/j.jconrel.2006.06.017, indexed in Pubmed: 16876898.

24. Huang YC, Yang YC, Yang KC, et al. Pegylated gold nanoparticles induce apoptosis in human chronic myeloid leukemia cells. Biomed Res Int. 2014; 2014: 182353, doi: 10.1155/2014/182353, indexed in Pubmed: 24790990.

25. Liu CJ, Wang CH, Chen ST, et al. Enhancement of cell radiation sensitivity by pegylated gold nanoparticles. Phys Med Biol. 2010; 55(4): 931-945, doi: 10.1088/0031-9155/55/4/002, indexed in Pubmed: 20090183.

26. Chen HH, Chien CC, Petibois C, et al. Quantitative analysis of nanoparticle internalization in mammalian cells by high resolution X-ray microscopy. J Nanobiotechnology. 2011; 9: 14, doi: 10.1186/1477-3155-9-14, indexed in Pubmed: 21477355.

27. Fruijtier-Pölloth C. Safety assessment on polyethylene glycols (PEGs) and their derivatives as used in cosmetic products. Toxicology. 2005; 214(1-2): 1-38, doi: 10.1016/j. tox.2005.06.001, indexed in Pubmed: 16011869.

28. Liu CJ, Yang TY, Wang CH, et al. Enhanced photocatalysis, colloidal stability and cytotoxicity of synchro- tron X-ray synthesized $\mathrm{Au} / \mathrm{TiO} 2$ nanoparticles. Materials Chemistry and Physics. 2009; 117(1): 74-79, doi: 10.1016/j. matchemphys.2009.05.030.

29. Liu CJ, Wang CH, Chien CC, et al. Enhanced x-ray irradiation-induced cancer cell damage by gold nanoparticles treated by a new synthesis method of polyethylene glycol modification. Nanotechnology. 2008; 19(29): 295104, doi: 10.1088/09574484/19/29/295104, indexed in Pubmed: 21730596.

30. Wang CH, Liu CJ, Wang CL, et al. Optimizing the size and surface properties of polyethylene glycol (PEG)-gold nanoparticles by intense $\mathrm{x}$-ray irradiation. J Physics D: Applied Physics. 2008; 41(19): 195301, doi: 10.1088/00223727/41/19/195301.

31. Wang CH, Liu CJ, Chien CC, et al. X-ray synthesized PEGylated (polyethylene glycol coated) gold nanoparticles in mice strongly accumulate in tumors. Mat Chem Phys. 2011; 126(1-2): 352-356, doi: 10.1016/j.matchemphys. 2010.11.014.

32. Nogueira-Pedro A, Cesário TA, Dias CC, et al. Hydrogen peroxide ( $\mathrm{H} 2 \mathrm{O} 2)$ induces leukemic but not normal hematopoietic cell death in a dose-dependent manner. Cancer Cell Int. 2013; 13(1): 123, doi: 10.1186/1475-2867-13-123, indexed in Pubmed: 24365069.

33. Liu Y, Liu $\mathrm{Wb}$, Liu $\mathrm{Kj}$, et al. Effect of $50 \mathrm{~Hz}$ extremely low-frequency electromagnetic fields on the DNA methylation and DNA methyltransferases in mouse spermatocyte-derived cell line GC-2. Biomed Res Int. 2015; 2015 : 237183, doi: 10.1155/2015/237183, indexed in Pubmed: 26339596.

34. Arellanes-Robledo J, Márquez-Rosado L, Pérez-Carreón JI, et al. Celecoxib induces regression of putative preneoplastic lesions in rat liver. Anticancer Res. 2006; 26(2A): 1271-1280, indexed in Pubmed: 16619534.

35. Carrasco-Legleu CE, Márquez-Rosado L, Fattel-Fazenda S, et al. Chemoprotective effect of caffeic acid phenethyl ester on promotion in a medium-term rat hepatocarcinogenesis assay. Int J Cancer. 2004; 108(4): 488-492, doi: 10.1002/ijc.11595, indexed in Pubmed: 14696111.

36. Márquez-Rosado L, Trejo-Solís MC, García-Cuéllar CM, et al. Celecoxib, a cyclooxygenase-2 inhibitor, prevents induction of liver preneoplastic lesions in rats. J Hepatol. 2005; 43(4): 653-660, doi: 10.1016/j.jhep.2005.02.032, indexed in Pubmed: 16023763.

Submitted: 24 April, 2019

Accepted after reviews: 12 November, 2019 Available as AoP: 20 November, 2019 